\title{
Theoretical Model and Experimental Investigations on Solution-Mediated Polymorphic Transformation of Theophylline: From Polymorph I to Polymorph II
}

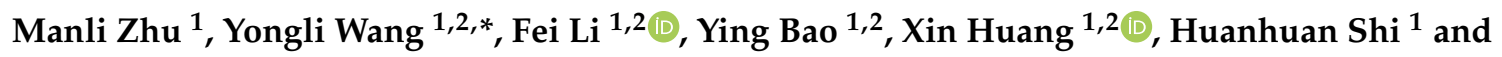 \\ Hongxun Hao ${ }^{1,2, *(D)}$ \\ 1 National Engineering Research Center of Industrial Crystallization Technology, School of Chemical \\ Engineering and Technology, Tianjin University, Tianjin 300072, China; 2016207163@tju.edu.cn (M.Z.); \\ lifeijessie@tju.edu.cn (F.L.); yingbao@tju.edu.cn (Y.B.); x_huang@tju.edu.cn (X.H.); Juana@tju.edu.cn (H.S.) \\ 2 Collaborative Innovation Center of Chemical Science and Engineering (Tianjin), Tianjin 300072, China \\ * Correspondence: yliwang@tju.edu.cn (Y.W.); hongxunhao@tju.edu.cn (H.H.); \\ Tel./Fax: +86-22-27374971 (H.H.)
}

Received: 8 May 2019; Accepted: 17 May 2019; Published: 19 May 2019

\begin{abstract}
In this work, theophylline was selected as the model compound to study and simulate the solution-mediated polymorphic transformation. The polymorph I and polymorph II of theophylline were prepared and fully characterized. Raman and UV spectra methods were carried out to observe the phase transformation of theophylline from polymorph I to polymorph II at different temperatures. The theoretical models, including dissolution model, nucleation model, and growth model, were established to describe and simulate the transformation processes. By combination of experiments and simulations, the controlling steps of the transformation processes were discussed. The effects of temperature and/or solvent on the transformation processes were evaluated. This work can shed light on the polymorphic transformation processes.
\end{abstract}

Keywords: theophylline; polymorphic transformation; temperature; solvent; mathematical model

\section{Introduction}

Most drugs are in crystalline form, and previous studies have shown that $80-90 \%$ of organic compounds have polymorphism [1]. Generally, physicochemical properties of pharmaceutical compounds vary with their polymorphs, which are tightly related to pharmaceutical properties, such as bioavailability and efficacy of the active pharmacutical ingredient (API) [2]. In order to ensure the high quality of pharmaceutical products and repeatability of production, it is important to improve the stability of the drug crystal form. For instance, polymorphic transformation has a large effect on the shelf life of the drug [3]. Considering that solution-mediated phase transformation is commonly observed during pharmaceutical production [4], a good understanding of the thermodynamic and kinetic properties of the solution-mediated polymorphic transformation is essential for the determination of the most thermodynamically stable form at room temperature during drug development and production to ensure the quality of the drug [5].

The polymorphic phase transition behavior occurring in solution mainly includes: (i) Dissolution of metastable phase, (ii) nucleation of the more stable phase, and (iii) growth of the more stable phase [6-8]. These three steps are all affected by operational factors, e.g., solvent, seed crystal, stirring speed, temperature, and impurities [9], among which solvent and temperature are the most important ones. Maher et al. [10] systematically studied the transition of piracetam from metastable polymorph II to stable polymorph III in seven solvents. It was found that the rate of crystal polymorphic transformation was related to the stirring speed, temperature, the solubility of piracetam in different 
solvents, and the interaction between piracetam and solvent. Liang Zhu et al. [11] reported that the polymorph I and polymorph II of gestodene were enantiotropic forms, and the crystal transformation temperature was $18.5 \pm 0.5^{\circ} \mathrm{C}$. The investigation on operational factors favors the regulation and optimization of the crystal transformation process and further improves the stability of the drug and the efficacy of a pharmaceutical API. [12-14]. However, although solution-mediated polymorphic transformation has been intensively investigated by experiments, its theoretical models are not well established due to the complexity of the transformation process.

In this work, to better understand the polymorphic transformation process, the solution-mediated polymorphic transformation was both theoretically and experimentally investigated by using theophylline (1,3-Dimethyl-3,7-dihydro-1H-purine-2,6-dione, $\mathrm{C}_{7} \mathrm{H}_{8} \mathrm{~N}_{4} \mathrm{O}_{2}$, Figure 1) as model compound. Owing to significant anti-inflammatory and immunomodulatory effects, theophylline is used as a bronchodilator for chronic lung disease and asthma. Theophylline has four crystal polymorphs [15], in which crystal polymorphs I and II are common pharmaceuticals. Literature $[15,16]$ showed that polymorph I would gradually transform to polymorph II, which is thermodynamically more stable during downstream processing or storage. However, the affecting factors and kinetics of theophylline transformation from polymorph I to polymorph II have not been reported. In this study, these two polymorphs of theophylline were firstly prepared and characterized by different methods. Then, the solution-mediated polymorphic transformation from polymorph I to polymorph II was studied both experimentally and theoretically. The mathematical models, including models of dissolution, nucleation, and growth, were built to simulate transformation processes, and the effects of various factors (e.g., system temperature, solvent) on the transformation processes were evaluated by both simulation and Raman spectroscopy.

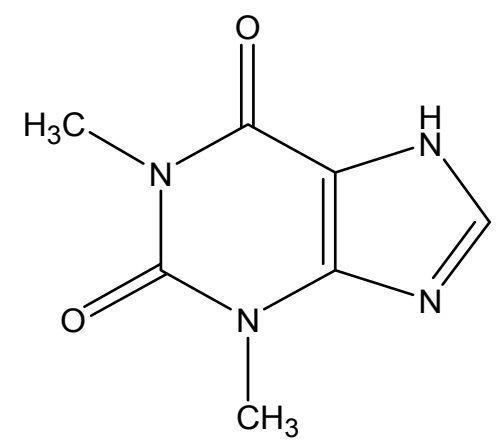

Figure 1. Chemical structure of theophylline.

\section{Experimental Section}

\subsection{Materials}

The solid-state theophylline polymorph II ( $\geq 99 \%$ mass fraction purity) was supplied by Shanghai Aladdin Bio-Chem Technology Co., Ltd. (Shanghai, China) and used without further purification. Methanol, ethanol, and isopropanol were purchased from Tianjin Kemat Chemical Technology Co., Ltd. (Tianjin, China) and used without further purification. The crystals of the polymorph I were prepared using a muffle furnace to calcine the raw materials at $270{ }^{\circ} \mathrm{C}$ for $2 \mathrm{~h}$ under the protection of circulating nitrogen.

\subsection{Characterization Methods}

\subsubsection{PXRD}

The powder X-ray diffraction (PXRD) patterns of polymorph I and polymorph II of theophylline were obtained by D/max-2500 diffractometer (Rigaku, Tokyo, Japan, $100 \mathrm{~mA}, 40 \mathrm{KV}$ ) at $2 \theta$ range from $2^{\circ}$ to $40^{\circ}$ with a scanning rate of $8^{\circ} / \mathrm{min}$. 


\subsubsection{SEM}

Scanning electron microscopy (SEM) (Jeol Electron Microscope; JSM 1600 Jeol Ltd., Tokyo, Japan) was carried out to identify the morphology of crystals. The samples were mounted on an aluminum stub with double adhesive tape and then coated with a thin gold layer (Jeol Fine coat, JFC 1100, Ion sputter; Jeol Ltd., Tokyo, Japan). The scanning voltage of the electron beam was $1.2 \mathrm{kV}$.

\subsubsection{TGA}

Thermogravimetric analysis (TG, Mettler Toledo TGA/DSC/SF, Greifensee, Switzerland) was carried out to determine the decomposition temperature of polymorph I and polymorph II of theophylline. The samples $(5-10 \mathrm{mg})$ were put into an aluminum pan and then heated at a ramping rate of $10{ }^{\circ} \mathrm{C} \cdot \mathrm{min}^{-1}$ from $25^{\circ} \mathrm{C}$ to $300^{\circ} \mathrm{C}$ under the flow of $\mathrm{N}_{2}\left(50 \mathrm{~mL} \cdot \mathrm{min}^{-1}\right)$.

\subsubsection{Raman Spectroscopy}

Raman spectrometer (Kaiser Raman RXN2, Kaiser Optical Systems, Inc., Ann Arbor, MI, USA) was used for in situ monitoring the phase transformation of theophylline. It was constituted with both an MR probe head and a PhAT probe head, and the excitation wavelength was $785 \mathrm{~nm}$. The intensity of Raman characteristic peak of the measured solid is linear with its corresponding content [17] and thus can be used to represent the contents of the two polymorphs. In this work, the characteristic peaks of crystal polymorph I at $1329 \mathrm{~cm}^{-1}$ and crystal polymorph II at $1664 \mathrm{~cm}^{-1}$ were used to in situ monitor the polymorphic transformation.

\subsubsection{FTIR}

Fourier-transform infrared spectroscopy (Thermo Fisher Scientific, Waltham, MA, USA) was used to obtain the concentrations of solution in this work. It was measured at the wavenumber range of 4000 to $400 \mathrm{~cm}^{-1}$ by using $\mathrm{KBr}$ disk method [2].

\subsection{Solution Concentration Measurements}

The real-time determination of the concentrations of theophylline in solution during polymorphic transformation was carried out by UV spectroscopic method. In the crystal transformation experiments, the stirring was stopped every $30 \mathrm{~min}$, and the suspension solution was allowed to stand for $5 \mathrm{~min}$. Then, the supernatant liquid was taken up by a filter $(0.22 \mu \mathrm{m}$, Tianjin, China) and weighed. Finally, the solution was appropriately diluted so that the UV (UV-3010 spectrophotometer, Tokyo, Japan) peak intensity of the solution was between 0.2 and 0.8 to ensure the accuracy of the experimental concentrations [18]. The concentration was determined at the maximum absorption wavelength of theophylline $(250 \mathrm{~nm})$. Furthermore, the solubilities of polymorph I and polymorph II of theophylline in methanol at 20,30, and $40{ }^{\circ} \mathrm{C}$ were respectively worked out and compared with literature [19] to further ensure the availability and accuracy of the experimental method. The average deviation between the measured data and the original data turned out less than 0.05 . Thus, the solubility measurement method used in this work is suitable for theophylline.

\subsection{Polymorphic Transformation Experiments}

The polymorphic transformation experiments were performed in a jacketed crystallizer $(100 \mathrm{~mL})$. First, $1 \mathrm{~g}$ theophylline polymorph I was added into $50 \mathrm{~g}$ methanol at $25^{\circ} \mathrm{C}, 30^{\circ} \mathrm{C}$, and $35^{\circ} \mathrm{C}$ to prepare the corresponding initial suspensions to study the influence of temperatures. Then, $1 \mathrm{~g}$ theophylline polymorph I was added into $50 \mathrm{~g}$ methanol, ethanol, and isopropanol at $30^{\circ} \mathrm{C}$ to study the influence of solvents. A thermostat bath (Julabo CF41, Julabo $\mathrm{GmbH}$, Seelbach, Germany, $\pm 0.01^{\circ} \mathrm{C}$ ) was used to control the temperature of the system. MR probe of Raman RXN2 was inserted into crystallizer to obtain the characteristic peak intensity changes of two polymorphs. The concentration was obtained 
by UV spectroscopic data simultaneously. In addition, PXRD analysis was also applied to identify the polymorphs of the solid samples [20].

\subsection{Theoretical Model}

The crystallization kinetics of theophylline in solution can be obtained by analyzing the three steps in the transformation process mentioned in the introduction. The undissolved theophylline solid over time can be described as a combination of the three steps [21,22]

$$
\frac{d A_{d}}{d t}=-\frac{d A_{s}}{d t}=\text { dissolution }- \text { growth }- \text { nucleation }
$$

where $A_{d}(\mathrm{~mol})$ is the amount of dissolved solid and $A_{S}(\mathrm{~mol})$ is the amount of undissolved solid.

Assuming that the sizes of all particles do not change during dissolution process, and the solids are monodisperse, the dissolution rate can be considered to be directly proportional to the amount of solid and expressed as Equation (2)

$$
D_{i}=K_{\text {diss }, i} A_{s, i}
$$

where $D_{i}\left(\mathrm{~mol} \cdot \mathrm{min}^{-1}\right)$ represents dissolution rate of the polymorph I; $K_{\text {diss }}\left(\mathrm{min}^{-1}\right)$ is the dissolution rate constant, which is related to the properties of particle and medium, such as particle size, diffusion layer thickness, and diffusivity; and $i$ stands for the solid form in suspension.

The nucleation of polymorph II can be described by the process that solute molecules spontaneously aggregate onto existing polymorph I particles after the induction period. Thus, nucleation can be considered as a polymolecular dynamics encounter probability event and expressed as Equation (3)

$$
J_{i}= \begin{cases}0 & , \quad t<t_{\text {ind }} \\ K_{n u c, i} \cdot V \cdot C^{\alpha, i} & , \quad t \geq t_{\text {ind }}\end{cases}
$$

where $J_{i}\left(\mathrm{~mol} \cdot \mathrm{min}^{-1}\right)$ stands for the nucleation rate of the polymorph II; $t_{\text {ind }}(\mathrm{min})$ is the induction period determined by experimental data, representing the time elapsed from formation of crystalline supersaturation to appearance of a new phase; $K_{n u c}\left(\mathrm{~min}^{-1} \cdot[\mathrm{L} / \mathrm{mol}]^{\alpha-1}\right)$ is the nucleation rate constant, indicating the possibility of forming aggregates; $V(\mathrm{~L})$ is the volume of solvent; $\alpha$ is the nucleation molecularity index, which represents the average number of molecules involved in nucleation.

Regarding the growth of polymorph II, the discrete dissolved theophylline tends to accumulate onto an already existing particle. Thus, the growth rate will be proportional to both the amount of solid and the concentration of dissolved theophylline. See Equation (4)

$$
G_{i}=K_{\text {growth }, i} \cdot A_{s, i} \cdot \mathrm{C}
$$

where $G_{i}\left(\mathrm{~mol} \cdot \mathrm{min}^{-1}\right)$ stands for the crystal growth rate of the polymorph II; $K_{\text {growth }}\left(\mathrm{L} \cdot \mathrm{mol}^{-1} \cdot \mathrm{min}^{-1}\right)$ is the growth rate constant, which denotes the reaction rate of the particles with dissolved theophylline; $\mathrm{C}\left(\mathrm{mol} \cdot \mathrm{L}^{-1}\right)$ is the solution concentration.

Accordingly, the undissolved theophylline over time is expressed specifically as Equation (5)

$$
-\frac{d A_{s, i}}{d t}= \begin{cases}K_{\text {diss }, i} \cdot A_{s, i}-K_{\text {growth }, i} \cdot A_{s, i} \cdot C & , t<t_{\text {ind }} \\ K_{\text {diss }, i} \cdot A_{s, i}-K_{\text {growth }, i} \cdot A_{s, i} \cdot C-K_{n u c, i} \cdot V \cdot C^{\alpha, i} & , t \geq t_{\text {ind }}\end{cases}
$$

where $i=1,2$, represents the two polymorphs of theophylline.

Substituting $C=A_{d} / V$ into Equation (1), the equation can be expressed as follows

$$
V \frac{d C}{d t}=-\sum_{i=1}^{n} \frac{d A_{s, j}}{d t}
$$


where $n=2$ and $i=1,2$.

When the solid and liquid phases reach equilibrium, the nucleation period is negligible [23]. At this point, the particle growth rate and dissolution rate remain in a state of equilibrium. Thus, solubility $C_{s o l}$ is replaced as Equation (7):

$$
C_{\text {sol, } i}=\frac{K_{\text {diss }, i}}{K_{\text {growth }, i}}
$$

After the combination of Equations (5) to (7), the following equations can be obtained

$$
\begin{gathered}
\frac{d C}{d t}= \begin{cases}\sum_{i=1}^{n} \frac{K_{\text {growth }, i} \cdot A_{s, i} \cdot\left(C_{\text {sol }, i}-C\right)}{V} & , t<t_{\text {ind }} \\
\sum_{i=1}^{n}\left(\frac{K_{\text {growth }, i} \cdot A_{s, i} \cdot\left(C_{\text {sol }, i}-C\right)}{V}-K_{n u c, i} \cdot C^{\alpha, i}\right), & t \geq t_{\text {ind }}\end{cases} \\
\frac{d A_{s, i}}{d t}= \begin{cases}-K_{\text {growth }, i} \cdot A_{s, i} \cdot\left(C_{s o l, i}-C\right) & t<t_{\text {ind }} \\
-V \cdot\left(\frac{K_{\text {growth }, i} \cdot A_{s, i} \cdot\left(C_{s o l, i}-C\right)}{V}-K_{n u c, i} \cdot C^{\alpha, i}\right), & t \geq t_{\text {ind }}\end{cases}
\end{gathered}
$$

where $i=1,2$.

During the simulation study, the experimentally measured solution concentration was substituted into the mathematical model to simulate the solid content of two polymorphs over time. Since the solid contents of two polymorphs are proportional to the relative intensities of the corresponding Raman characteristic peaks, the change trend of solid contents was represented by that of the relative intensity of the corresponding Raman characteristic peak. MATLAB (2015) was used to simulate the phase transformation of theophylline, and eight parameters were estimated by least square method using nonlinear dynamic parameter fitting procedure. The ordinary differential equations with variable integration step was solved by ode45 function.

\section{Results and Discussion}

\subsection{Characterizations}

As shown in Figure 2, polymorph I can be verified by the peaks at diffraction angle (20) of $11.66^{\circ}$ and $14.92^{\circ}$, and polymorph II at $7.08^{\circ}$ and $12.54^{\circ}$. The results are identical to the literature data [24]. SEM was applied to show the morphologies of the two polymorphs. In Figure 3, polymorph I has a plate-like shape, whereas polymorph II exhibits a needle-like morphology. The TGA, FTIR, and Raman results are shown in Figures 4-6. Figure 4 indicates that the decomposition temperatures of the two polymorphs are close to each other (polymorph I, $\sim 275^{\circ} \mathrm{C}$; polymorph II, $\sim 270^{\circ} \mathrm{C}$ ), which are consistent with data in reference [15]. As can be seen in Figure 5, the FTIR spectra of the two polymorphs are generally similar but differ in some characteristic peaks (e.g., polymorph I, $1148 \mathrm{~cm}^{-1}$; polymorph II, $868 \mathrm{~cm}^{-1}$ ). The Raman spectra of two polymorphs are shown in Figure 6 and significant differences can be observed between many characteristic peaks of two crystal polymorphs. Thus, Raman can be applied to analyze the changes in solid content by using the characteristic peaks at $1329 \mathrm{~cm}^{-1}$ and $1664 \mathrm{~cm}^{-1}$ to detect crystal polymorph I and II, respectively. As shown in Figure 7, both crystal polymorphs of theophylline show an increasing solubility with the increase of temperature, and solubility of polymorph I is always higher than that of polymorph II in investigated temperature ranges. 


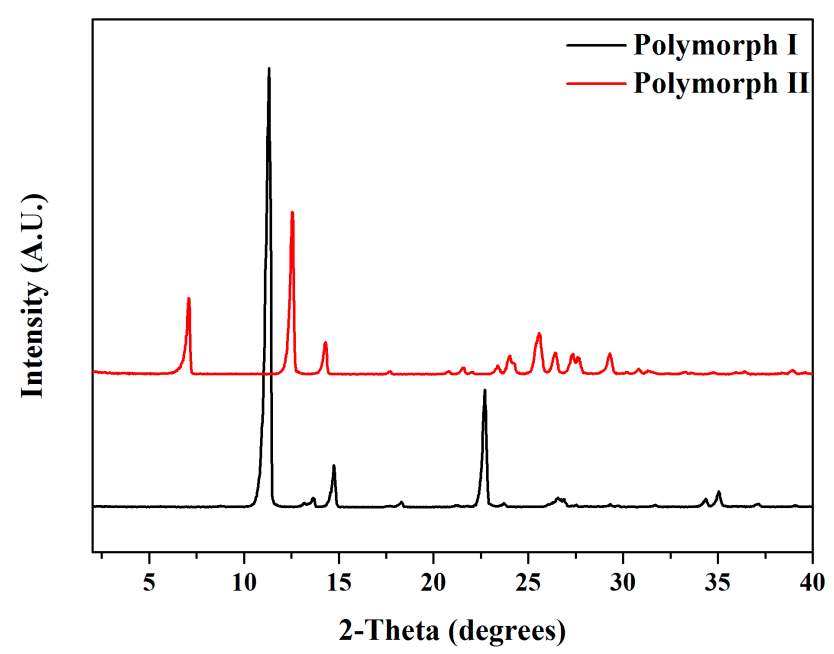

Figure 2. Powder X-ray diffraction (PXRD) of polymorph I and polymorph II of theophylline.
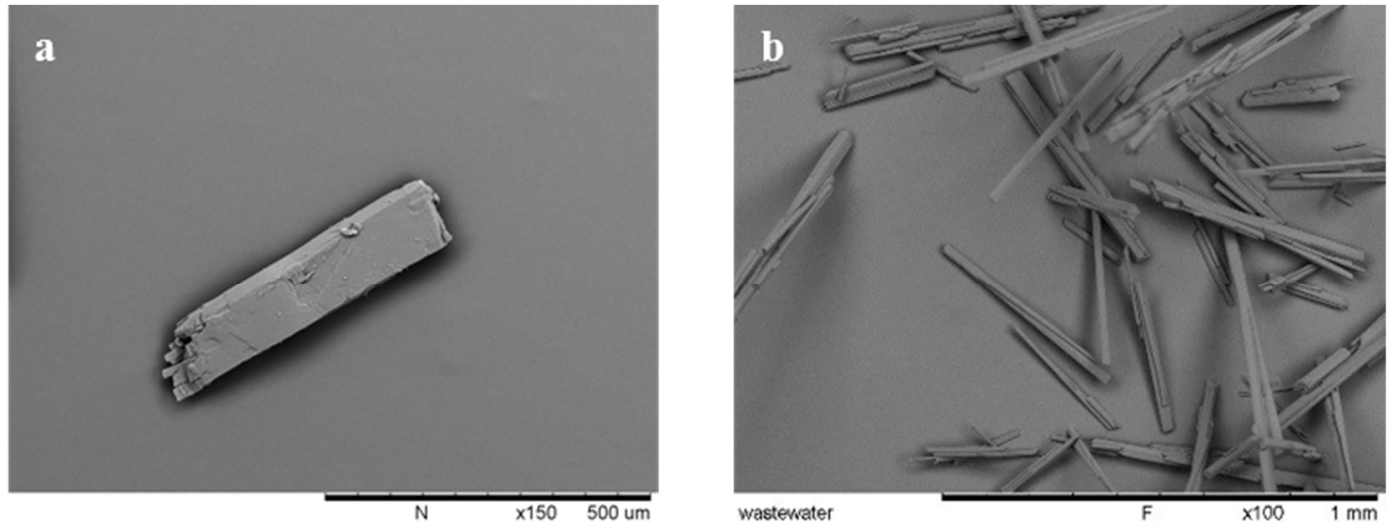

Figure 3. SEM of theophylline. (a) Polymorph I; (b) polymorph II.

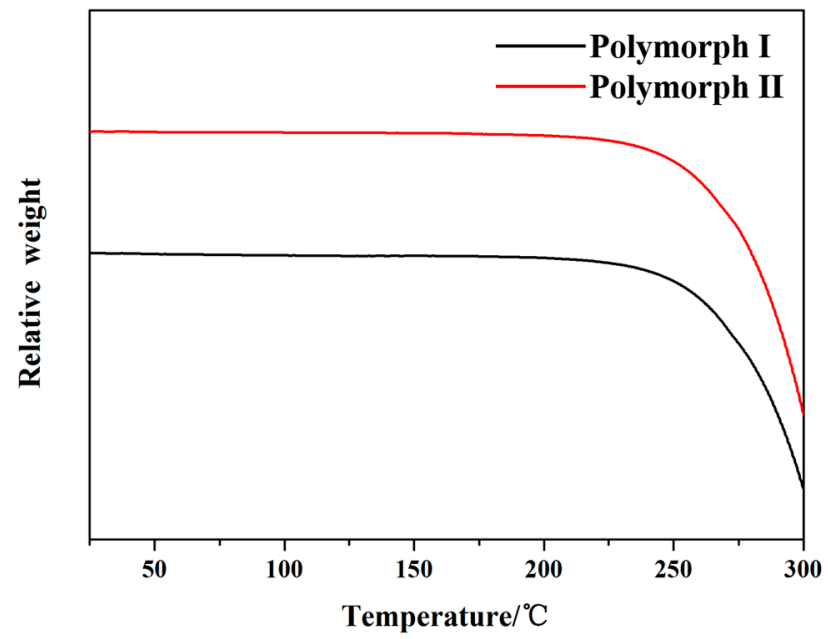

Figure 4. TGA graphs of polymorph I and polymorph II of theophylline. 


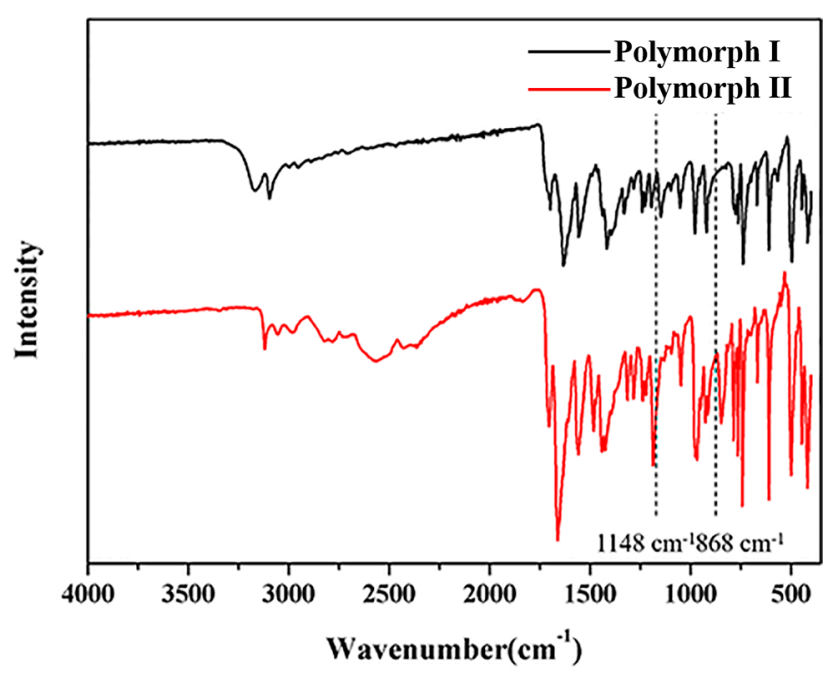

Figure 5. FTIR spectra of polymorph I and polymorph II of theophylline.

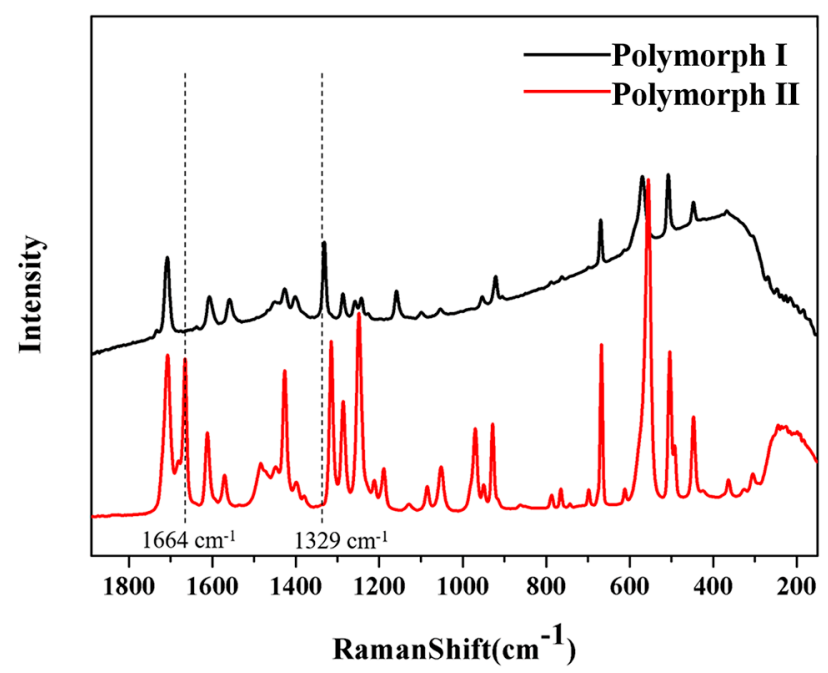

Figure 6. Raman spectra of polymorph I and polymorph II of theophylline.

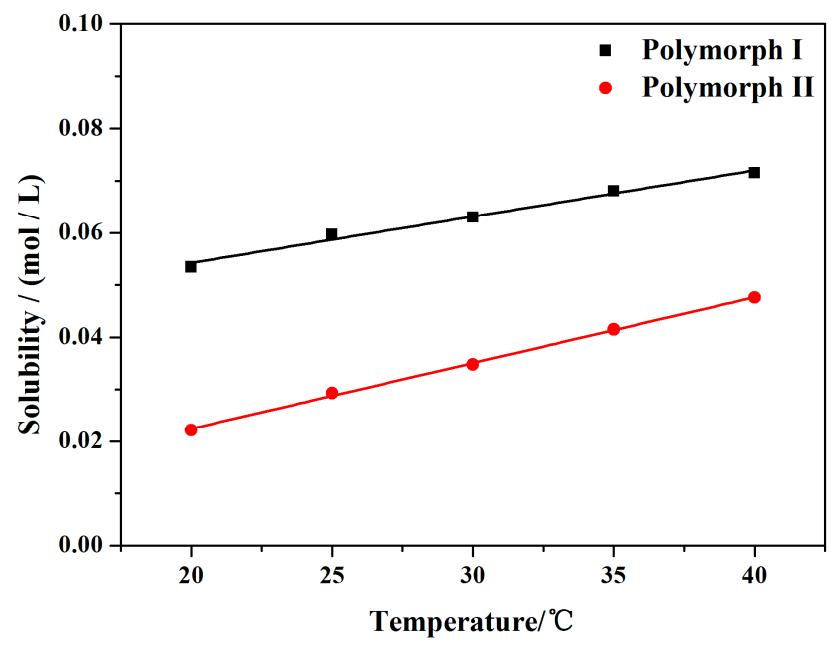

Figure 7. Solubility of polymorph I and polymorph II of theophylline in methanol. 


\subsection{Solution-Mediated Transformation}

Raman and UV spectroscopic methods were carried out to characterize the transformation behavior of different theophylline polymorphs. First, as can be seen from Figure 8, after the addition of solid polymorph I into methanol, the induction time decreases with temperature increasing. The solid content of polymorph I (Raman at $1329 \mathrm{~cm}^{-1}$ ) decreased gradually, and that of polymorph II (Raman at $1664 \mathrm{~cm}^{-1}$ ) increased consequently. Meanwhile, the solution concentration of suspension system also underwent a decreasing process first and then tended to be stable, which was due to the fact that the system was initially saturated solution of theophylline polymorph I and finally transformed to saturated solution of polymorph II as the crystal transformation occurred. It should be noted that the solution concentration first decreased quickly and then gradually slowed down, a result of the slow dissolution rate of theophylline solid-state polymorph I. Thus, it can be concluded that nucleation and dissolution of polymorph I are the control steps at the early and late stages of solution-mediated transformation of theophylline, respectively.

a

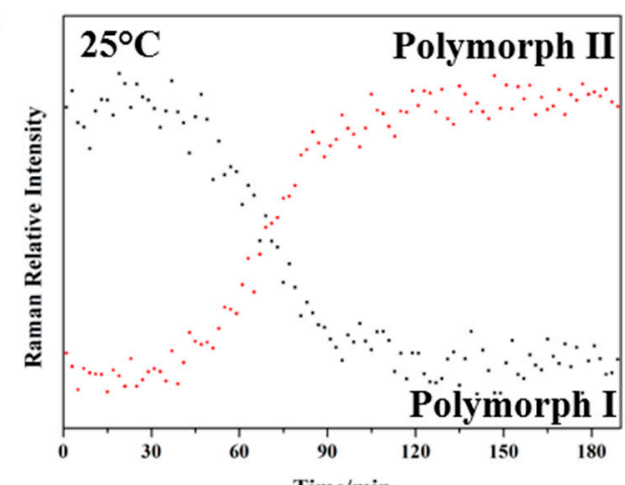

c

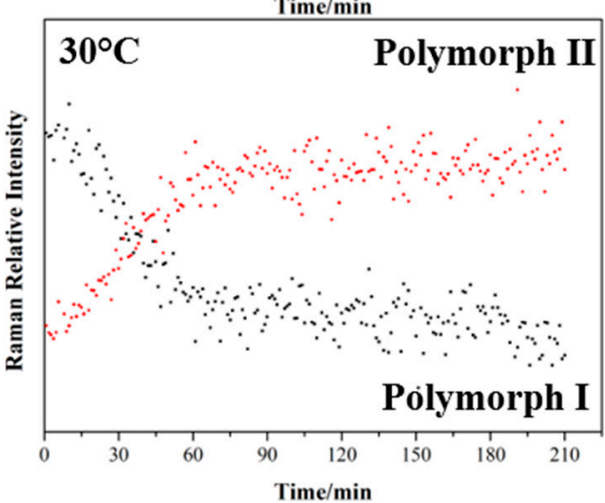

e

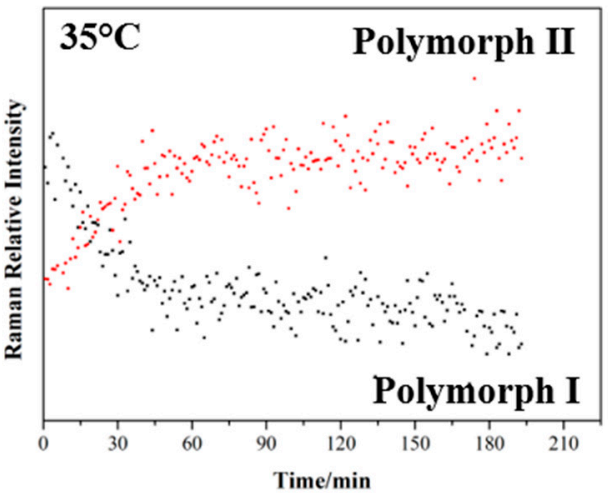

b

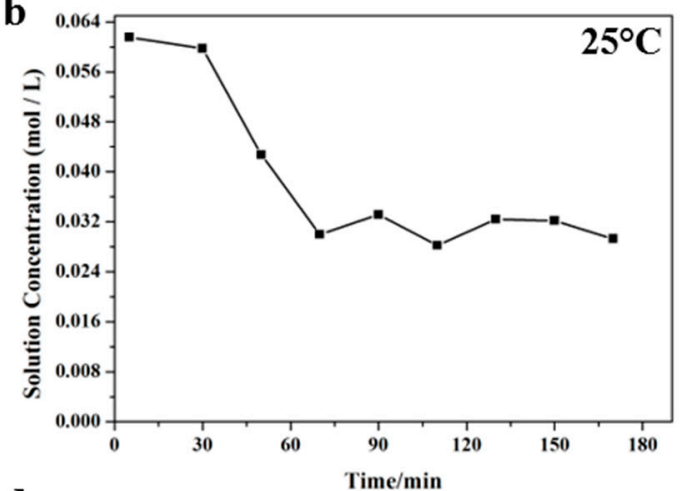

d
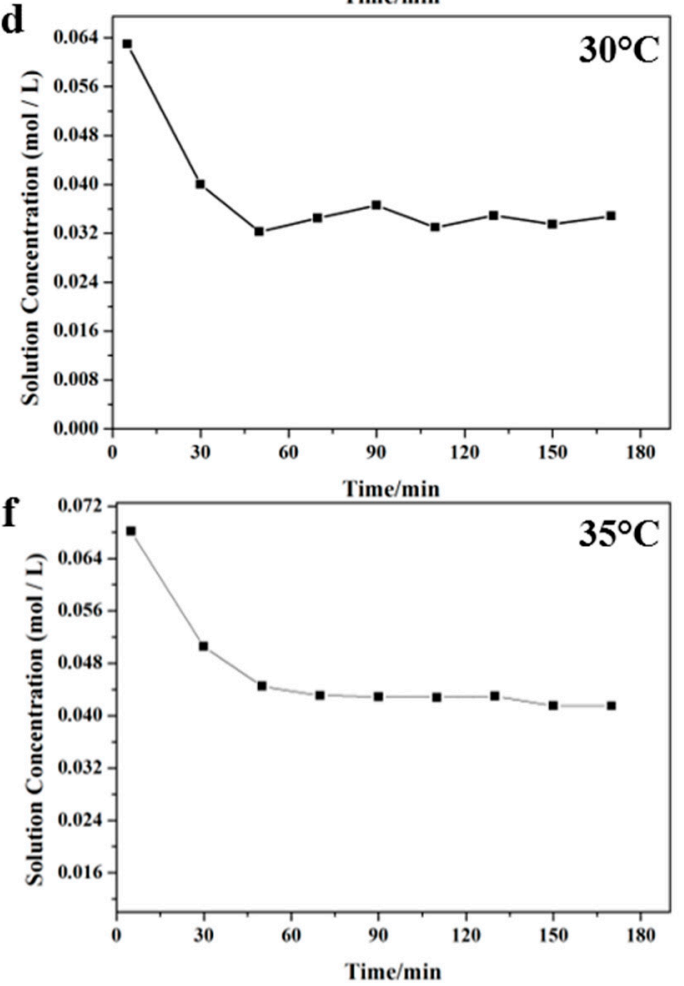

Figure 8. Solution-mediated polymorphic transformation between two polymorphs of theophylline in methanol at various temperatures. Profiles of solid composition at $25^{\circ} \mathrm{C}, 30^{\circ} \mathrm{C}$, and $35^{\circ} \mathrm{C}$ are shown in $(\mathbf{a}, \mathbf{c}, \mathbf{e})$, respectively. $(\mathbf{b}, \mathbf{d}, \mathbf{f})$ are their solution concentrations, respectively. 
According to Figure 9, the characteristic peaks of polymorph I gradually decrease with time prolonging, and the characteristic peaks of polymorph II increase accordingly. The two forms coexisted in the sample obtained after $40 \mathrm{~min}$, whereas form II was the only species after $100 \mathrm{~min}$. Therefore, the results of PXRD matched well with those of Raman.

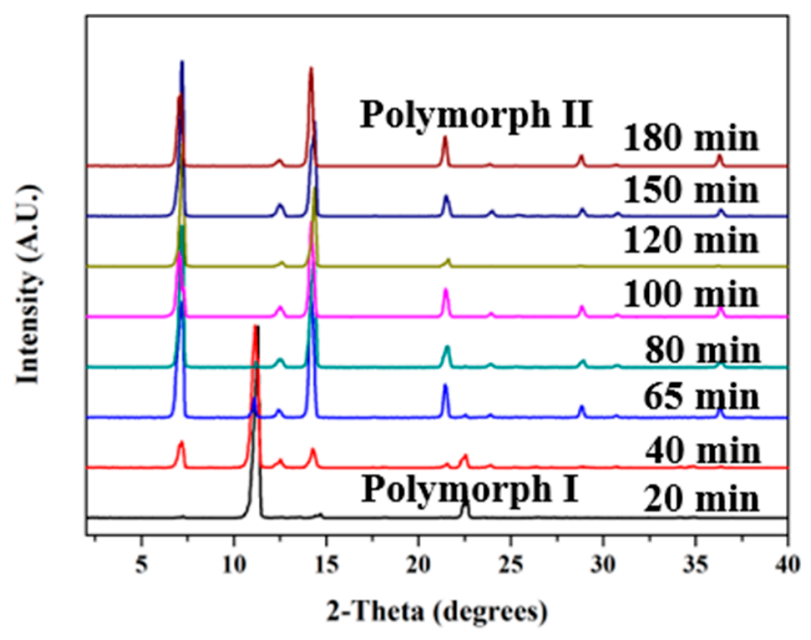

Figure 9. PXRD patterns of samples obtained in the polymorphic transformation of theophylline in methanol at $30^{\circ} \mathrm{C}$.

\subsubsection{Influence of System Temperature}

Despite the fact that polymorph I would spontaneously transform to polymorph II, different operating factors have influence on the kinetics of transformation. In this work, the influences of system temperature and type of solvent were investigated.

The results of transformation in methanol at different system temperatures have been shown in Figure 8. It can be seen that temperature can affect induction period (nucleation) and the total duration of transformation processes. Lower temperature turns out to result in longer transformation time: $120 \mathrm{~min}$ at $25^{\circ} \mathrm{C}, 75 \mathrm{~min}$ at $30^{\circ} \mathrm{C}$, and $45 \mathrm{~min}$ at $35^{\circ} \mathrm{C}$. These results are reasonable if considering that higher temperature will speed up dissolution, nucleation and growth of particles.

\subsubsection{Influence of Solvent}

The experimental results obtained at $30{ }^{\circ} \mathrm{C}$ in different solvents are shown in Figure 10. The transformation process turns out to be related to the solvent. The induction time in methanol at $30{ }^{\circ} \mathrm{C}$ is $12 \mathrm{~min}$, in ethanol $50 \mathrm{~min}$, and in isopropanol $400 \mathrm{~min}$. Since the induction time has close relationships with the nucleation rate, and the latter is positively related to the supersaturation ratio of solution, the induction time varies with the supersaturation ratio of different solvent systems. On the other hand, in Figure 10, the time for completion of crystal transformation of theophylline in three solvents is $75 \mathrm{~min}, 200 \mathrm{~min}$, and $400 \mathrm{~min}$, respectively, that is, the transformation of theophylline in methanol is the fastest while the transformation in isopropanol is the slowest. The results could be explained by different solubilities of the two polymorphs in different solvents. 


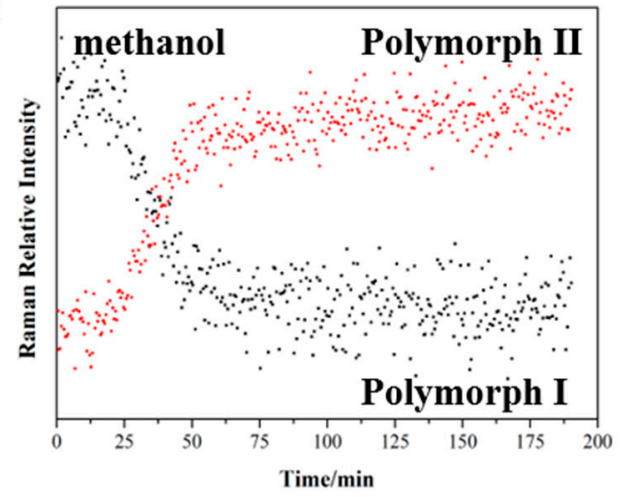

b

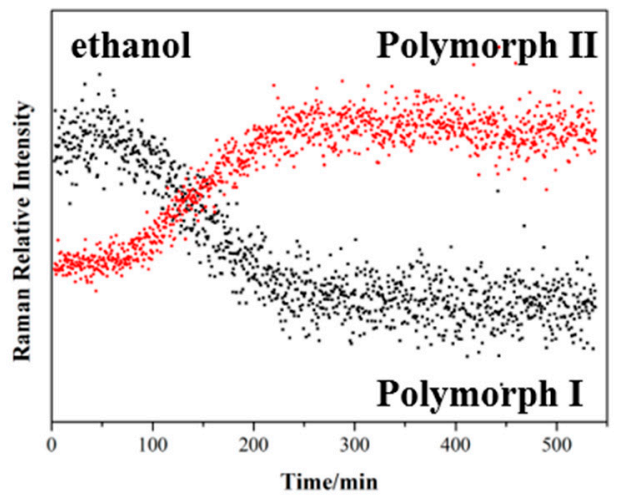

c

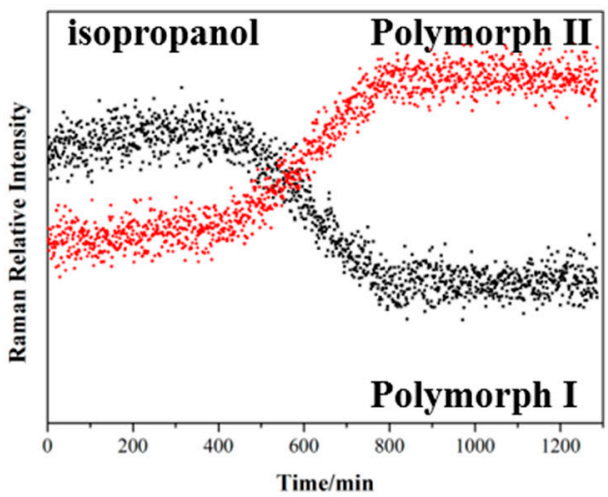

Figure 10. Solution-mediated polymorphic transformation between two polymorphs of theophylline at $30{ }^{\circ} \mathrm{C}$ in various solvents. $(\mathbf{a}-\mathbf{c})$ are profiles of solid composition in methanol, ethanol, isopropanol, respectively.

\subsection{Transformation Process Models and Simulation}

The kinetic models described above were utilized for illustration of the polymorphic transformation of theophylline in methanol at different temperatures. The parameters of solid-state kinetic models were obtained by nonlinear correlations of experimental data and are listed in Table 1 . The values of $K_{\text {diss }}, K_{n u c}$ and $K_{\text {growth }}$ all turn out to vary with temperatures. The corresponding rate constants increase with the increasing of system temperature. At the same time, the growth rate of crystal polymorph II is much faster than the dissolution rate of crystal polymorph I. Thus, after polymorph II nucleates, the concentration of solution reduces rapidly in the late stage of transformation, which also supports the conclusion that solution-mediated transformation of theophylline in methanol is a "dissolution-controlled" process at the late stage of transformation.

Table 1. Parameters for Theophylline in various temperatures in solution-mediated transformation processes.

\begin{tabular}{ccccccc}
\hline Temperatures & Solid Forms & $\begin{array}{c}\boldsymbol{K}_{\text {diss }} \\
\left(\mathbf{m i n}^{-1}\right)\end{array}$ & $\begin{array}{c}C_{\text {sol }} \\
(\mathbf{m o l} / \mathbf{L})\end{array}$ & $\begin{array}{c}K_{\text {growth }} \\
(\mathbf{L} /[\mathbf{m o l} \cdot \mathbf{m i n}])\end{array}$ & $\begin{array}{c}k_{\text {nuc }} \\
\left(\mathbf{m i n}^{-\mathbf{1}} \cdot[\mathrm{L} / \mathbf{m o l}]^{\alpha-1}\right)\end{array}$ & $\alpha$ \\
\hline \multirow{2}{*}{$25^{\circ} \mathrm{C}$} & Polymorph I & $1.38 \mathrm{e}^{-2}$ & $1.12 \mathrm{e}^{-1}$ & $1.23 \mathrm{e}^{-1}$ & $1.98 \mathrm{e}^{-1}$ & 5.01 \\
& Polymorph II & $1.28 \mathrm{e}^{-2}$ & $9.41 \mathrm{e}^{-2}$ & $1.36 \mathrm{e}^{-1}$ & $1.12 \mathrm{e}^{-1}$ & 1.48 \\
$30{ }^{\circ} \mathrm{C}$ & Polymorph I & $4.04 \mathrm{e}^{-2}$ & $2.02 \mathrm{e}^{-1}$ & $2.00 \mathrm{e}^{-1}$ & $8.96 \mathrm{e}^{-2}$ & 3.31 \\
& Polymorph II & $3.06 \mathrm{e}^{-2}$ & $1.85 \mathrm{e}^{-1}$ & $1.65 \mathrm{e}^{-1}$ & $1.36 \mathrm{e}^{-1}$ & 1.30 \\
$35{ }^{\circ} \mathrm{C}$ & Polymorph I & $7.72 \mathrm{e}^{-2}$ & $3.84 \mathrm{e}^{-1}$ & $2.01 \mathrm{e}^{-1}$ & $9.73 \mathrm{e}^{-2}$ & 3.20 \\
& Polymorph II & $3.45 \mathrm{e}^{-2}$ & $2.09 \mathrm{e}^{-1}$ & $1.65 \mathrm{e}^{-1}$ & $1.19 \mathrm{e}^{-1}$ & 1.32 \\
\hline
\end{tabular}

The models were used to simulate the transformation processes. The simulated solution concentrations in these three experiments and the simulated solid contents of undissolved solid 
phase were worked out for comparison with the experimental results (Figure 11). The change trend of simulated solid contents of theophylline polymorphs mostly agrees with the experimental compositions reflected by Raman. The simulated solution concentrations also fit well with the experimental data. The simulation results indicate that the solution-mediated transformation of theophylline at 25, 30 and $35^{\circ} \mathrm{C}$ in methanol is a dissolution-controlled process once nucleation happens. Thus, the nucleation and growth of the more stable polymorph II will rapidly consume the liquid theophylline, which causes a rapid drop in the concentration of solution. The liquid concentration will reach the solubility of polymorph II at the end of the transformation.

a

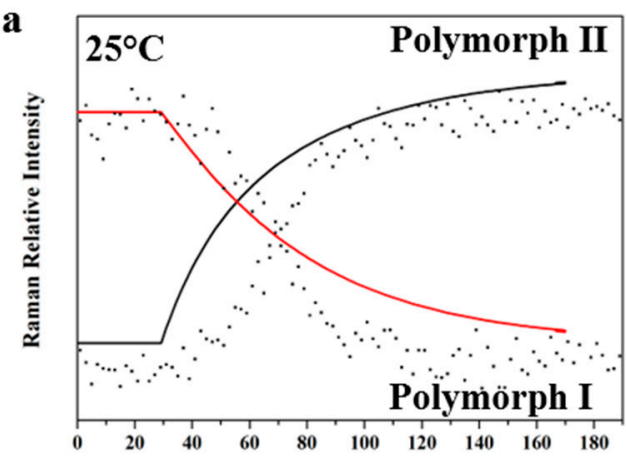

c

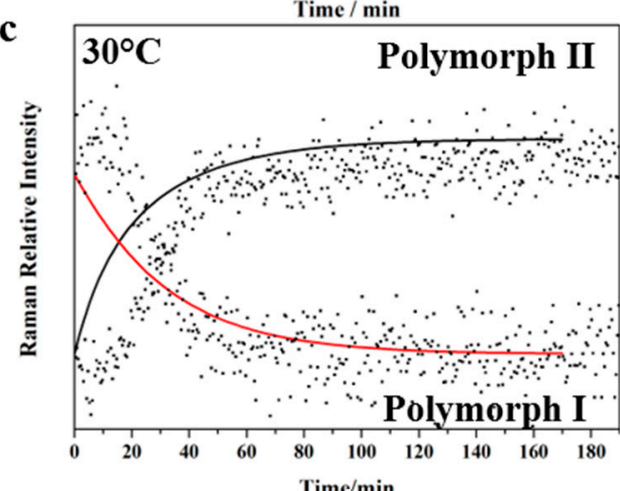

e

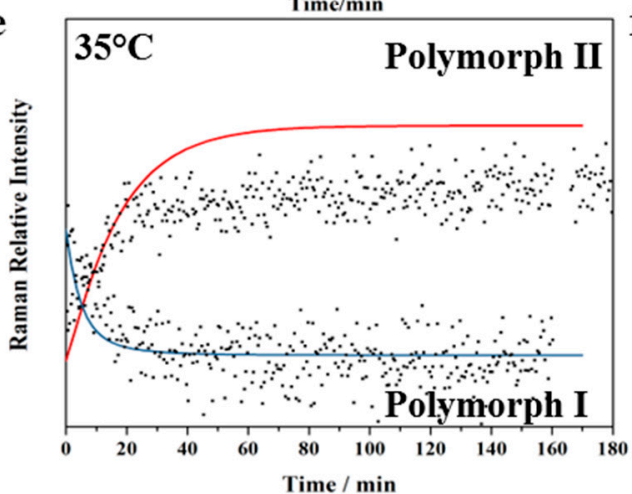

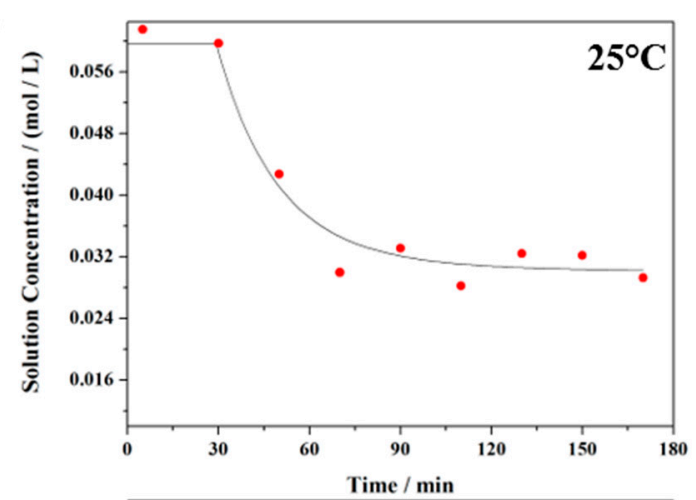

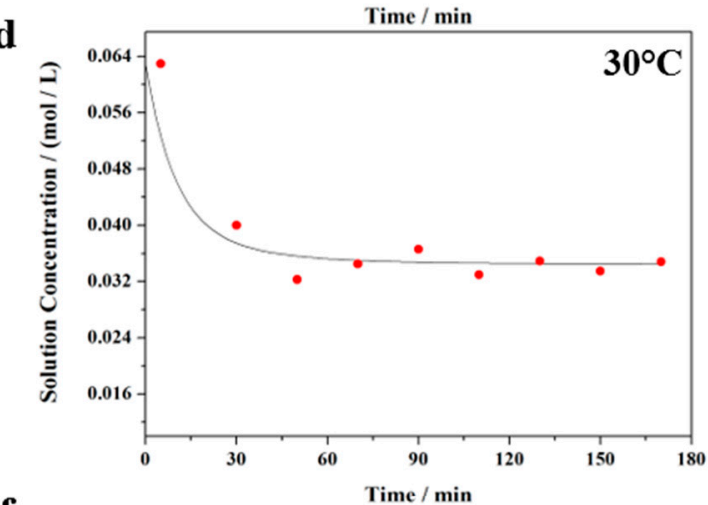

f

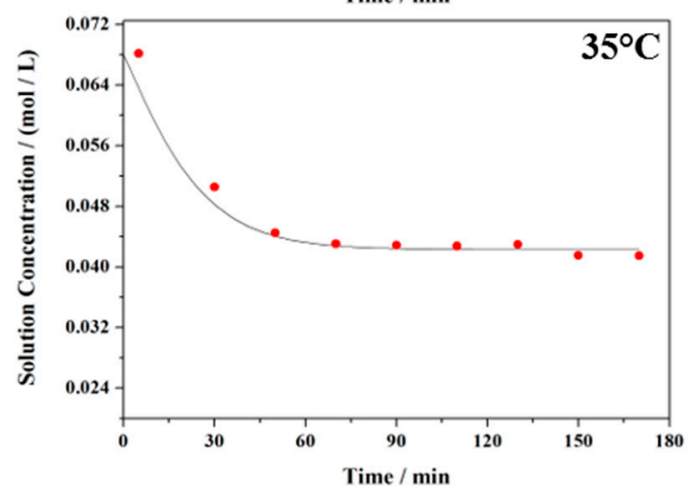

Figure 11. Experimental and simulated solid composition profiles: (a) $25^{\circ} \mathrm{C}$, (c) $30^{\circ} \mathrm{C}$, (e) $35^{\circ} \mathrm{C}$; and solution concentration profiles (b) $25^{\circ} \mathrm{C},(\mathbf{d}) 30^{\circ} \mathrm{C},(\mathbf{f}) 35^{\circ} \mathrm{C}$ during the transformation processes in methanol at different system temperatures. All the experimental data are shown as square and the simulated results are shown as solid lines.

The average relative deviation (ARD, Equation (10)) and root-mean-square deviation (RMSD, Equation (11)) were used to examine the models [25].

$$
A R D=\frac{1}{N} \sum_{i=1}^{N}\left|\frac{x_{i}^{c a l}-x_{i}^{\exp }}{x_{i}^{\exp }}\right|
$$




$$
R M S D=\sqrt{\frac{\sum_{i=1}^{N}\left(x_{i}^{c a l}-x_{i}^{\exp }\right)^{2}}{N}}
$$

where $N$ represents the number of experimental solution concentration points, $x^{\text {cal }}$ is the simulated concentration, $x^{\exp }$ is the experimental concentration.

The values of ARD and RMSD are listed in Table 2. The RMSD data at different temperatures are very small, and all the ARD between the experimental data and the simulated data are all less than $5.52 \%$, indicating that the model can give a good fitting result. The negligible differences between the experimental and the simulated data are mainly caused by the assumptions, such as the uniform size distribution of all particles, with which the calculation can be significantly simplified. Overall, results indicate that the model can serve as a useful tool to both simulate the solution-mediated processes of theophylline and evaluate the effect of temperature.

Table 2. Average relative deviation (ARD) and root-mean-square deviation (RMSD) of the simulated results.

\begin{tabular}{ccc}
\hline Temperatures & $\mathbf{1 0}^{\mathbf{2}} \mathbf{A R D}$ & $\mathbf{1 0}^{\mathbf{3}} \mathbf{R M S D}$ \\
\hline $25^{\circ} \mathrm{C}$ & 5.48 & 2.19 \\
$30^{\circ} \mathrm{C}$ & 5.52 & 3.89 \\
$35^{\circ} \mathrm{C}$ & 2.22 & 1.78 \\
\hline
\end{tabular}

\section{Conclusions}

The solution-mediated phase transformation of different polymorphs was experimentally and theoretically investigated by using theophylline as model compound. Two polymorphs of theophylline were prepared and characterized. The polymorphic transformation from polymorph I to polymorph II was monitored by using in situ Raman and UV spectroscopic methods. The theoretical models of the transformation processes were developed, and the influences of both system temperature and solvent on transformation were investigated. The results demonstrated that higher system temperature facilitated the transformation, and the transformation duration varied with different crystallization solvents. The transformation was fastest in methanol and slowest in isopropanol. In addition, the transformation process was controlled by nucleation at initial stage and then dissolution of polymorph I at late stage. Moreover, it was found that the simulated results are well-fitted to experimental ones, confirming that the models used in this study are reliable for simulation of the transformation processes. This study can provide reliable ways for better understanding the solution-mediated polymorphic transformation and guide the production of pharmaceutical products which exhibit polymorphic phenomena.

Author Contributions: Conceptualization, M.Z., Y.W., H.H.; methodology, M.Z., H.H.; formal analysis, F.L., Y.B., X.H.; investigation, M.Z., H.S..; writing-original draft preparation, M.Z.; supervision, Y.W., H.H.; project administration, M.Z., H.H.; funding acquisition, Y.W., H.H.; writing-review and editing, M.Z., F.L., Y.B., H.S., H.H.

Funding: This research was funded by the National Natural Science Foundation of China (Grant No. 21376165) and the Key Project of Tianjin Science and Technology Supporting Program (No. 13ZCZDNC02000).

Conflicts of Interest: The authors declare no competing financial interest.

\section{References}

1. Du, W.; Yin, Q.; Hao, H.; Bao, Y.; Zhang, X.; Huang, J.; Li, X.; Xie, C.; Gong, J. Solution-Mediated Polymorphic Transformation of Prasugrel Hydrochloride from Form II to Form I. Ind. Eng. Chem. Res. 2014, 53, 5652-5659. [CrossRef]

2. Guo, N.; Hou, B.; Wang, N.; Xiao, Y.; Huang, J.; Guo, Y.; Zong, S.; Hao, H. In Situ Monitoring and Modeling of the Solution-Mediated Polymorphic Transformation of Rifampicin: From Form II to Form I. J. Pharm. Sci. 2018, 107, 344-352. [CrossRef] 
3. Xu, Y.; Wu, S.-P.; Liu, X.-J.; Zhang, L.-J.; Lu, J. Crystal characterization and transformation of the forms I and II of anticoagulant drug rivaroxaban. Cryst. Res. Technol. 2017, 52, 1600379. [CrossRef]

4. Liu, Y.; Xu, S.; Liu, Y.; Chen, M.; Chen, Y.; Du, S.; Wang, Y.; Sun, P.; Sun, M.; Shi, P.; et al. Seed-Assisted Effects on Solution-Mediated Phase Transformation: A Case Study of 1-Histidine in Antisolvent Crystallization. Ind. Eng. Chem. Res. 2018, 57, 784-793. [CrossRef]

5. Wang, J.-R.; Zhu, B.; Zhang, Z.; Bao, J.; Deng, G.; Ding, Q.; Mei, X. Polymorphism of Triamcinolone Acetonide Acetate and Its Implication for the Morphology Stability of the Finished Drug Product. Cryst. Growth Des. 2017, 17, 3482-3490. [CrossRef]

6. Jiang, S.; Jansens, P.J.; ter Horst, J.H. Control over Polymorph Formation of o-Aminobenzoic Acid. Cryst. Growth Des. 2010, 10, 2541-2547. [CrossRef]

7. Liu, W.; Wei, H.; Black, S. An Investigation of the Transformation of Carbamazepine from Anhydrate to Hydrate Using in Situ FBRM and PVM. Org. Process Res. Dev. 2009, 13, 494-500. [CrossRef]

8. Maher, A.; Rasmuson, Å.C.; Croker, D.M.; Hodnett, B.K. Solubility of the Metastable Polymorph of Piracetam (Form II) in a Range of Solvents. J. Chem. Eng. Data 2012, 57, 3525-3531. [CrossRef]

9. Liu, Y.; Gao, H.; Xu, H.; Ren, F.; Ren, G. Influence of Temperature, Solvents, and Excipients on Crystal Transformation of Agomelatine. Org. Process Res. Dev. 2016, 20, 1559-1565. [CrossRef]

10. Maher, A.; Croker, D.M.; Seaton, C.C.; Rasmuson, Å.C.; Hodnett, B.K. Solution-Mediated Polymorphic Transformation: Form II to Form III Piracetam in Organic Solvents. Cryst. Growth Des. 2014, 14, 3967-3974. [CrossRef]

11. Zhu, L.; Wang, L.-Y.; Sha, Z.-L.; Wang, Y.-F.; Yang, L.-B.; Zhao, X.-Y.; Du, W. Interplay between Thermodynamics and Kinetics on Polymorphic Appearance in the Solution Crystallization of an Enantiotropic System, Gestodene. Cryst. Growth Des. 2017, 17, 4582-4595. [CrossRef]

12. Flood, A.E.; Wantha, L. Population balance modeling of the solution mediated transformation of polymorphs: Limitations and future trends. J. Cryst. Growth 2013, 373, 7-12. [CrossRef]

13. Rodríguez-Hornedo, N.; Murphy, D. Surfactant-facilitated crystallization of dihydrate carbamazepine during dissolution of anhydrous polymorph. J. Pharm. Sci. 2004, 93, 449-460. [CrossRef] [PubMed]

14. Zhao, J.; Wang, M.; Dong, B.; Feng, Q.; Xu, C. Monitoring the Polymorphic Transformation of Imidacloprid Using in Situ FBRM and PVM. Org. Process Res. 2013, 17, 375-381. [CrossRef]

15. Seton, L.; Khamar, D.; Bradshaw, I.; Hutcheon, G. Processing induced transformations: Phase impurities introduced during hydration/dehydration. Chem. Eng. Sci. 2012, 77, 57-64. [CrossRef]

16. Fucke, K.; McIntyre, G.J.; Wilkinson, C.; Henry, M.; Howard, J.A.K.; Steed, J.W. New Insights into an Old Molecule: Interaction Energies of Theophylline Crystal Forms. Cryst. Growth Des. 2012, 12, 1395-1401. [CrossRef]

17. Chen, Y.; Dai, L. A Method for the Quantitative Analysis of a Key Component in Complex Mixtures Using Raman Spectroscopy Based on Peak Decomposition. Anal. Sci. 2019, 35, 511-515. [CrossRef]

18. Weinstein, R.D.; Hanlon, W.H.; Donohue, J.P.; Simeone, M.; Rozich, A.; Muske, K.R. Solubility of Felodipine and Nitrendipine in Liquid and Supercritical Carbon Dioxide by Cloud Point and UV Spectroscopy. J. Chem. Eng. Data 2007, 52, 256-260. [CrossRef]

19. Seton, L.; Khamar, D.; Bradshaw, I.J.; Hutcheon, G.A. Solid State Forms of Theophylline: Presenting a New Anhydrous Polymorph. Cryst. Growth Des. 2010, 10, 3879-3886. [CrossRef]

20. Wu, S.; Du, S.; Chen, M.; Li, K.; Jia, L.; Zhang, D.; Macaringue, E.G.J.; Hou, B.; Gong, J. Crystal Structures and Phase Behavior of Sulfadiazine and a Method for the Preparation of Aggregates with Good Performance. Chem. Eng. Technol. 2018, 41, 532-540. [CrossRef]

21. Fagerberg, J.H.; Sjogren, E.; Bergstrom, C.A.S. Concomitant intake of alcohol may increase the absorption of poorly soluble drugs. Eur. J. Pharm. Sci. 2015, 67, 12-20. [CrossRef] [PubMed]

22. Takano, R.; Sugano, K.; Higashida, A.; Hayashi, Y.; Machida, M.; Aso, Y.; Yamashita, S. Oral absorption of poorly water-soluble drugs: Computer simulation of fraction absorbed in humans from a miniscale dissolution test. Pharm. Res. 2006, 23, 1144-1156. [CrossRef] [PubMed]

23. Jakubiak, P.; Wagner, B.; Grimm, H.P.; Petrig-Schaffland, J.; Schuler, F.; Alvarez-Sánchez, R. Development of a Unified Dissolution and Precipitation Model and Its Use for the Prediction of Oral Drug Absorption. Mol. Pharm. 2016, 13, 586-598. [CrossRef] [PubMed] 
24. Khamar, D.; Bradshaw, I.J.; Hutcheon, G.A.; Seton, L. Solid State Transformations Mediated by a Kinetically Stable Form. Cryst. Growth Des. 2012, 12, 109-118. [CrossRef]

25. Li, R.; Zhan, S.; Chen, G.; Jin, Y.; Yu, B.; Zhao, J.; Han, D.; Fan, H. Equilibrium Solubility, Model Correlation, and Solvent Effect of Indole-3-acetic Acid in Twelve Pure Solvents. J. Chem. Eng. Data 2019, 64, 1802-1808. [CrossRef] 